\title{
Voltage variations identification using Gabor Transform and rule-based classification method
}

\author{
Weihown Tee ${ }^{1}$, M. R. Yusoff ${ }^{2}$, M. Faizal Yaakub ${ }^{3}$, A. R. Abdullah ${ }^{4}$ \\ ${ }^{1,4}$ Fakulti Kejuruteraan Elektrik, Universiti Teknikal Malaysia Melaka, Malaysia \\ ${ }^{2,3}$ Fakulti Teknologi Kejuruteraan Elektrik dan Elektronik, Universiti Teknikal Malaysia Melaka, Malaysia
}

\begin{tabular}{|c|c|}
\hline Article Info & ABSTRACT \\
\hline Article history: & This paper presents a comparatively contemporary easy to use technique for \\
\hline Received Jan 25, 2019 & $\begin{array}{l}\text { the identification and classification of voltage variations. The technique was } \\
\text { established based on the Gabor Transform and the rule-based classification }\end{array}$ \\
\hline Revised Oct 1, 2019 & method. The technique was tested by using mathematical model of Power \\
\hline Accepted Oct 10, 2019 & $\begin{array}{l}\text { Quality (PQ) disturbances based on the IEEE Std } 519-2009 \text {. The PQ } \\
\text { disturbances focused were the voltage variations, which included voltage sag, }\end{array}$ \\
\hline Keywords: & $\begin{array}{l}\text { swell and interruption. A total of } 80 \text { signals were simulated from } \\
\text { the mathematical model in MATLAB and used in this study. The signals }\end{array}$ \\
\hline Gabor transform & were analyzed by using Gabor Transform and the signal pattern, time- \\
\hline Power quality & $\begin{array}{l}\text { frequency representation (TFR) and root-mean-square voltage graph were } \\
\text { presented in this paper. The features of the analysis were extracted, and rules }\end{array}$ \\
\hline Power quality disturbances & were implemented in rule-based classification to identify and classify \\
\hline Rule-based method & $\begin{array}{l}\text { the voltage variation accordingly. The results showed that this method is easy } \\
\text { to be used and has good accuracy in classifying the voltage variation. }\end{array}$ \\
\hline
\end{tabular}

Copyright (C) 2020 Institute of Advanced Engineering and Science. All rights reserved.

\section{Corresponding Author:}

\author{
A. R. Abdullah, \\ Fakulti Kejuruteraan Elektrik, \\ Universiti Teknikal Malaysia Melaka, \\ Jalan Hang Tuah Jaya, 76100 Durian Tunggal, Melaka, Malaysia. \\ Email: abdulr@utem.edu.my
}

\section{INTRODUCTION}

Power Quality (PQ) has become a critical issue for users and the adequacy. Power signals can be crooked with different types of PQ disturbances such as the voltage variations (voltage sag, swell and interruption), harmonics, transient and so on: where the quality of the signal can be impaired [1]. PQ disturbance is basically explained as any change of voltage, current or frequency in power that affects the normal operation of the machine or equipment [2]. Electrical device or equipment used in the industries are sensitive to the occurrence of PQ disturbances, which will bring impact to economic losses [3]. So, PQ is becoming one of an important issues in modern power systems [4].

To ensure PQ in the distribution systems, performance monitoring of the power system is required [5]. So, researchers have proposed time-frequency analysis methods to monitor and analyze PQ disturbance signals. The features of the signals will be extracted from the time-frequency domains (TFDs) and be used to classify the events [6-21]. These approaches used a similar working scheme where signals monitored are first analyzed through TFD methods before extracting the features from the signals analyzed. From the literature, Fourier Transform (FT) is not suitable for analyzing non-stationary signals. Short-time Fourier Transform (STFT) is better than FT and yet still fails to obtain good time resolution in time and frequency domain. Wavelet Transform (WT) can extract the time and frequency information concurrently, however it is very sensitive to noise as well as the dependency of accuracy on selected mother wavelet. Spectrogram can perform better than previous methods, but its fixed window width cannot provide good time-frequency resolution. In order to overcome the limitation of spectrogram, Gabor Transform (GT) is 
introduced which able to detect spectrum changes with resolution under 20ms. However, there is less literature regarding GT based classification.

Researchers have used various techniques to detect and classify the PQ for example the rule-based method, artificial neural network (ANN), support vector machines (SVM) and so on [22-27]. ANN are mainly used for pattern matching, classification, optimizing and data clustering yet they are hard to debug with computationally intensive to train. SVM has regularization parameter, where it is an approximation with no local minima. However, it covers the determination of the parameters for value of regularization and kernel parameters which are sensitive to over-fitting model selection. Rule-based method is easy to be generated and interpreted which comparable to decision tree. From the literature, rule-based method is easy to be used and applied on a less complex domain.

Many techniques were presented by researchers for analyzing and classifying power quality problems. In this paper, GT technique is implemented to analyze the disturbances by representing the signals in time frequency representation (TFR). Then, the parameters obtained from the time-frequency representation (TFR) will be used as input for rule-based classifier to classify the PQ event. The attempt of this research is an investigation to seek an easier method without consuming much computation time for classifying PQ events by using GT.

\section{POWER QUALITY SIGNALS MODELS}

Power Quality (PQ) disturbances that may appear in a power system are different in their characteristics. IEEE Std. 1159-2009 explains the categories of PQ disturbances [28, 29]. In this paper, the type of disturbances focused is voltage variation which are the voltage sag, swell and interruption. Mathematical models with parameters are used for generating signals in MATLAB. The signals generated are of $50 \mathrm{~Hz}$ according to IEEE standard. The mathematical models and parameters of signals are tabulated in Table 1 [30]. Class symbol of $\mathrm{C} 1$ is used to categorize pure sine wave or voltage waveform in normal form while $\mathrm{C} 2$ to $\mathrm{C} 4$ are used to investigate PQ disturbances (voltage variations).

Table 1. Mathematical model of PQ disturbances [29]

\begin{tabular}{|c|c|c|c|c|}
\hline \multirow[t]{2}{*}{ PQ disturbance } & \multirow[t]{2}{*}{ Class symbol } & \multirow[t]{2}{*}{ Mathematical model } & \multicolumn{2}{|c|}{ Parameters } \\
\hline & & & Standard & Simulated \\
\hline Pure sine wave & $\mathrm{C} 1$ & $\mathrm{y}(\mathrm{t})=\mathrm{A} \sin (\mathrm{wt})$ & $\mathrm{w}=2 \pi \mathrm{f}$ & $\mathrm{A}=1 \mathrm{pu}, \mathrm{f}=50 \mathrm{~Hz}$ \\
\hline Voltage swell & $\mathrm{C} 2$ & $\mathrm{y}(\mathrm{t})=\mathrm{A}\left(1+\propto\left(\mathrm{u}\left(\mathrm{t}-\mathrm{t}_{1}\right)-\mathrm{u}\left(\mathrm{t}-\mathrm{t}_{2}\right)\right)\right) \sin (\mathrm{wt})$ & $\begin{array}{l}0.1 \leq \alpha \leq 0.9 \\
\mathrm{~T} \leq \mathrm{t}_{2}-\mathrm{t}_{1} \leq 9 \mathrm{~T}\end{array}$ & $\alpha=0.3, \mathrm{t}_{1}=0.05, \mathrm{t}_{2}=0.15$ \\
\hline Voltage sag & $\mathrm{C} 3$ & $\mathrm{y}(\mathrm{t})=\mathrm{A}\left(1-\propto\left(\mathrm{u}\left(\mathrm{t}-\mathrm{t}_{1}\right)-\mathrm{u}\left(\mathrm{t}-\mathrm{t}_{2}\right)\right)\right) \sin (\mathrm{wt})$ & $\begin{array}{l}0.1 \leq \alpha \leq 0.9 \\
\mathrm{~T} \leq \mathrm{t}_{2}-\mathrm{t}_{1} \leq 9 \mathrm{~T}\end{array}$ & $\alpha=0.3, \mathrm{t}_{1}=0.05, \mathrm{t}_{2}=0.15$ \\
\hline $\begin{array}{l}\text { Voltage } \\
\text { interruption }\end{array}$ & $\mathrm{C} 4$ & $\mathrm{y}(\mathrm{t})=\mathrm{A}\left(1-\propto\left(\mathrm{u}\left(\mathrm{t}-\mathrm{t}_{1}\right)-\mathrm{u}\left(\mathrm{t}-\mathrm{t}_{2}\right)\right)\right) \sin (\mathrm{wt})$ & $\begin{array}{l}\alpha \leq 0.1 \\
\mathrm{~T} \leq \mathrm{t}_{2}-\mathrm{t}_{1} \leq 9 \mathrm{~T}\end{array}$ & $\alpha=0.3, \mathrm{t}_{1}=0.05, \mathrm{t}_{2}=0.15$ \\
\hline
\end{tabular}

A: amplitude; f: frequency; y: voltage; T: period; t: time; w: angular frequency; $\alpha=$ voltage magnitude; $u(t)$ : unit step function

\section{POWER QUALITY ANALYSIS METHOD}

\subsection{Gabor transform}

A British physicist, Dennis Gabor suggested a signal processing transform method [31]. It expands a signal into set of functions that are concentrated in both frequency and time domains [12, 31]. The coefficients of the functions will then be used as the descriptors of local property of the particular signal [32]. Gabor transform uses hanning window just as spectrogram but different in terms of window length (480 samples) $[6,33]$. Hanning window is selected as window function due to its lower peak side lope which has narrow effect on other frequencies around fundamental value (50 Hz in this study). The Gabor Transform is represented as:

$$
G(t, f)=\left|\int_{-\infty}^{\infty} x(\tau) e^{\frac{-(\tau-t)^{2}}{2 \sigma^{2}}} e^{-j 2 \pi f \tau} d \tau\right|^{2}
$$

Where $x(\tau)$ is the input signal and $\sigma$ is sigma. The ordering of the matrices of GT can be presented as

$$
A=\left|\begin{array}{cccc}
A_{00} & A_{01} & \ldots & A_{N-4, N-1} \\
A_{10} & A_{11} & \ldots & \cdots \\
\cdots & A_{21} & A_{N-2, N-2} & \cdots \\
A_{N-1,0} & \cdots & A_{N-1, N-2} & A_{N-1, N-1}
\end{array}\right|
$$


Where $\mathrm{A}$ is the matrices associated with the matrix of window of GT time slice. The signal input processed by GT will be analyzed and presented in matrix form of MxN. The maximum values of the GT of the signal will be extracted from the matrices for further analysis.

\subsection{Calculation of root mean square (RMS) voltage}

Root-mean-square (RMS) is used for extracting information generally from PQ disturbances. Each type of PQ disturbance has its own symbolized RMS voltage waveforms [34-36]. RMS voltage can be practically derived from the time-frequency representation (TFR). The equation can be explained as:

$$
V_{r m s}(t)=\sqrt{\int_{0}^{f_{\max }} P_{x}(t, f) d f}
$$

Where $P_{x}(t, f)$ is the time-frequency distribution, $f_{\max }$ is the maximum frequency of interest.

\subsection{Rule-based classification technique}

The rule-based classifier basically consists of IF-THEN rules, where a bunch of facts and an interpreter are controlling the rules function or application, with facts applied. This classifier will classify test records based on the rules triggered [27, 37, 38]. The basic theory of rule-based classifier is shown in Figure 1.

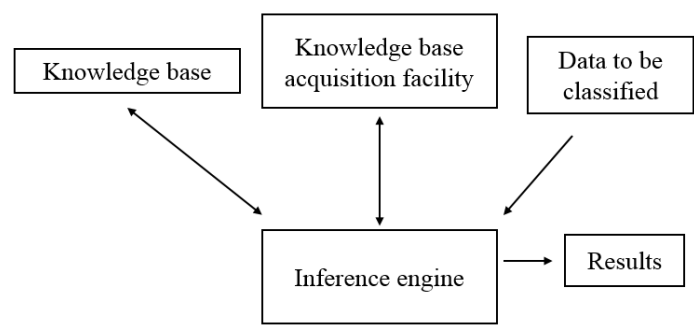

Figure 1. Structure of rule-based classifier

IF-THEN rule statements are used to develop the conditions or statements that compose the knowledge base. The knowledge base stores all relevant information (rules, data and so on) used by the system. IF-THEN rule presumes a condition where if $\mathrm{x}$ is $\mathrm{A}$, then $\mathrm{y}$ is $\mathrm{B}$. the if-part of rule $\mathrm{x}$ is called premise whereas the then-part of rule $y$ is called conclusion. The inference engine in this classifier is right-on according to the rules applied. Finally, the results of the classification will be presented differ in disturbance classes.

\section{RESULTS AND DISCUSSION}

The analysis of Gabor Transform on voltage variations will be detailed in this section. The matrix information acquired by Gabor Transform is used to obtain plots for detecting and classifying the PQ disturbances (voltage variations in this study). The plots obtained are amplitude plot, time-frequency contour plot, and RMS voltage per unit (pu) plot.

\subsection{Pure sine wave}

Figure 2 presents the Gabor Transform based plots of normal voltage or pure sine wave. The time-frequency representation (TFR) indicates the pure natural of the wave which drops on $50 \mathrm{~Hz}$. The RMS voltage pu graph shows constant amplitude of voltage at $1 \mathrm{pu}$ which shows and indicates normal voltage waveform. These will be used as reference for detecting voltage variation.

\subsection{Voltage swell}

Voltage swell and Gabor Transform based plots are shown in Figure 3. Increase in magnitude of voltage amplitude is effectively observed from the amplitude plot. From the TFR, the signal has an increment in magnitude between $0.05 \mathrm{~s}$ and $0.15 \mathrm{~s}$. The lighter the counter, the higher the magnitude of the signal and vice versa. The RMS voltage pu plot is plotted from the RMS calculation of TFR which shows increase of $0.5 \mathrm{vpu}$ at $0.05 \mathrm{~s}$ and drops back to normal amplitude (1vpu) at $0.15 \mathrm{~s}$. 

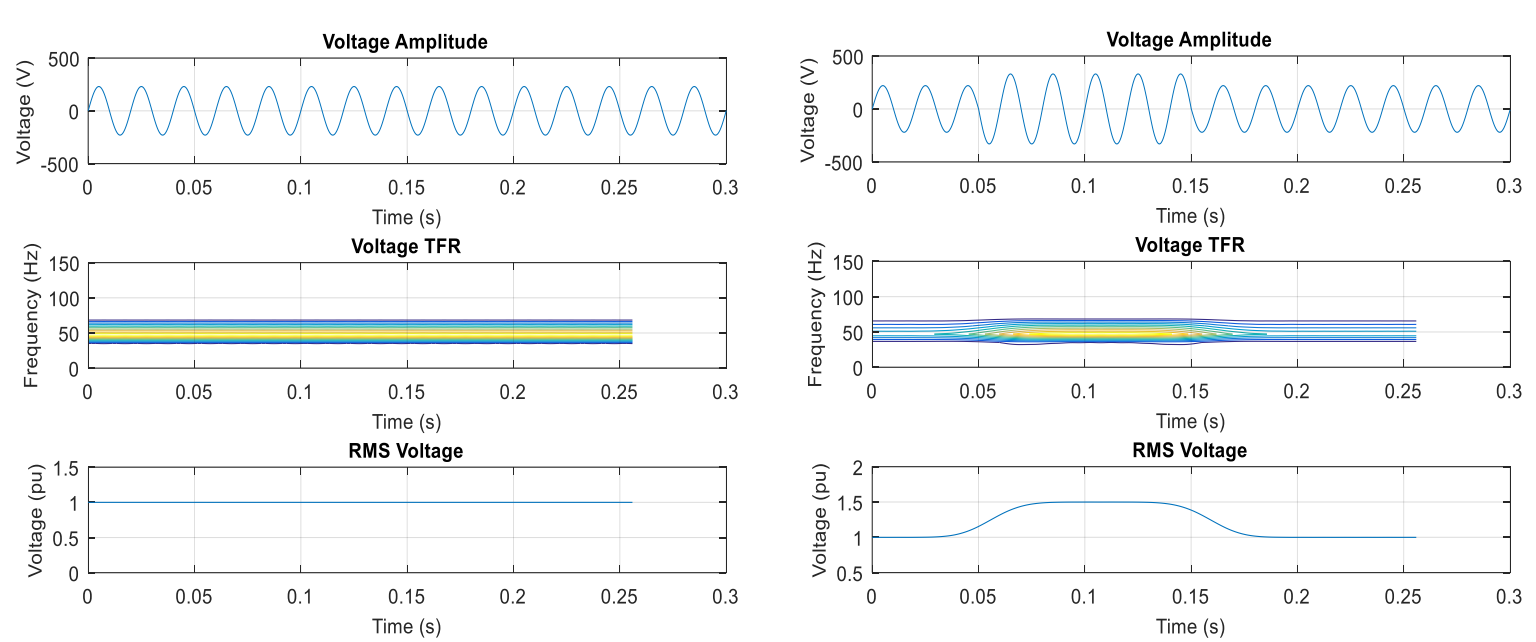

Figure 2. Gabor transform based plots for pure sine wave

Figure 3. Gabor Transform based plots for voltage swell

\subsection{Voltage sag}

Figure 4 depicted the voltage sag and its Gabor Transform based plots. Sag can be observed from the contour where the magnitude of the contour drops from $0.05 \mathrm{~s}$ to $0.15 \mathrm{~s}$ where yellow contour indicates higher magnitude while blue contour indicates lower magnitude. From the RMS voltage pu graph shows sag duration between $0.05 \mathrm{~s}$ to $0.15 \mathrm{~s}$ which helps to identify and detect the occurrence of voltage sag effectively.

\subsection{Voltage interruption}

Interruption of voltage can be observed in Figure 5. In voltage amplitude plot, there shows total interrupted voltage waveform from $0.05 \mathrm{~s}$ to $0.15 \mathrm{~s}$. A discontinuity in TFR contour from $0.05 \mathrm{~s}$ to $0.15 \mathrm{~s}$ shows that voltage interruption occurs where there is total loss in magnitude within the interruption period. The RMS voltage pug graph shows decrease of voltage as well to approximately zero during the interruption before returning to normal.
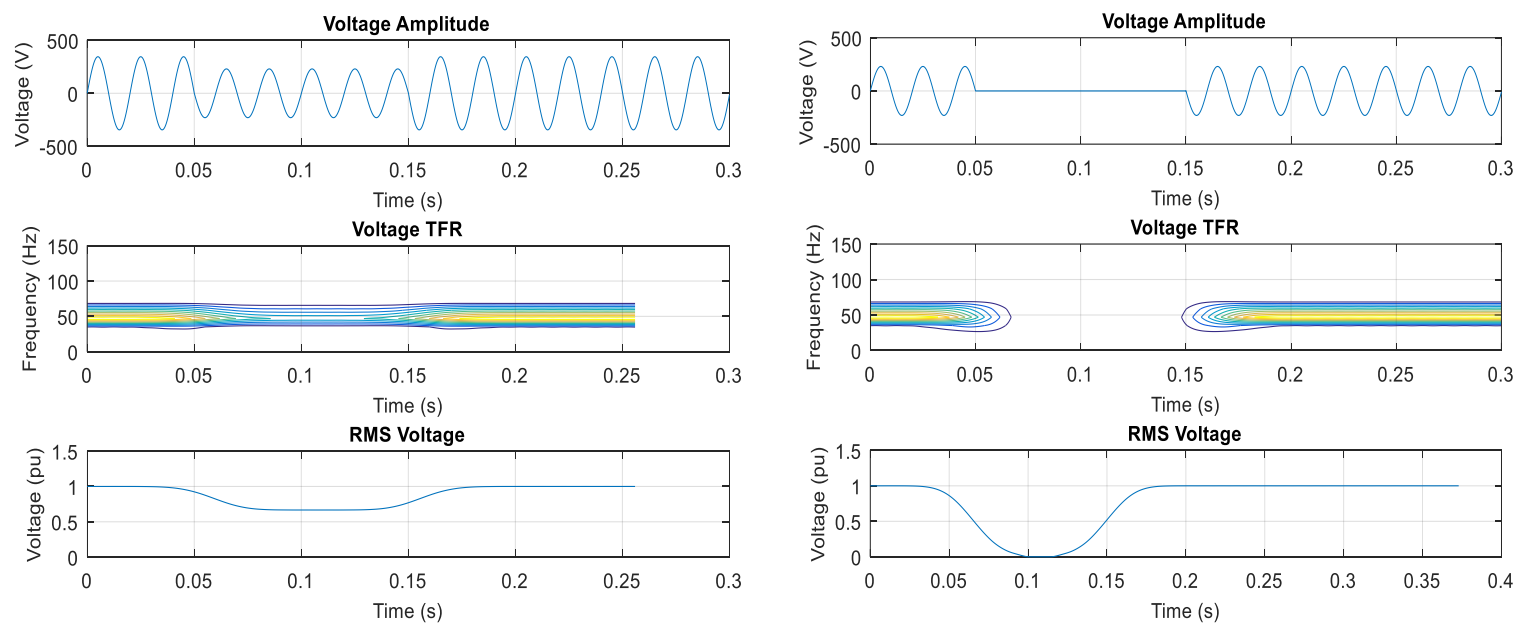

Figure 4. Gabor transform based plots for voltage sag

Figure 5. Gabor Transform based plots for voltage interruption

\subsection{Classification by using rule-based classifier}

In this study, the features which can characterize the PQ disturbances was developed based on the Gabor Transform contour. First, the RMS voltage was calculated from the TFR of GT as first set of features. These features will be used to identify the class of PQ disturbance based on the pattern of 
the waveform according to IEEE Standards. Then, the maximum values in GT matrix were extracted as second set of features. It is noted that the maximum values plotting of GT is closely resemble to the RMS voltage values plotting. The procedure of the classification process is presented as in Figure 6.

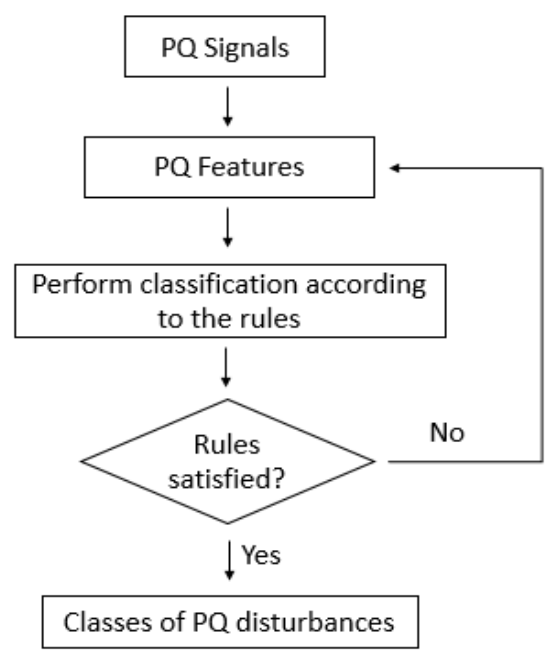

Figure 6. Flowchart of rule-based classifier

From these sets of features, four features namely F1, F2, F3 and F4 were selected. The characteristics of the features were selected accordingly from the maximum values plotting as stated in IEEE Std 519-2009, IEEE Recommended Practice for Monitoring Electric Power Quality. The features description is presented in Table 2. This study uses rule-based classifier to classify the PQ disturbance or the voltage variations events. The classification of voltage variations will be performed accordingly based on the IF-THEN rules as presented in Table 3.

Table 2. Description of features

\begin{tabular}{cl}
\hline Features & Description \\
\hline F1 & Values for data below 0.90 in the graph of maximum values \\
F2 & Values for data above 1.10 in the graph of maximum values \\
F3 & The minimum values below 0.90 in the graph of maximum values \\
F4 & The maximum values above 1.10 in the graph of maximum values \\
\hline
\end{tabular}

Table 3. Description of rules

\begin{tabular}{cl}
\hline Rules & Description \\
\hline R1 & If $(F 1=0),(F 2=0),(0.90<F 3<1.10)$ and $(0.90<F 4<1.10)$ then output is C1 (Pure Sine Wave) \\
R2 & If $(F 1>0)$ or $(F 2>0),(0.90<F 3<1.10)$ and $(\mathrm{F} 4>1.10)$ then output is C2 (Voltage Swell) \\
R3 & If $(F 1>0)$ or $(F 2>0),(F 3<0.90)$ and $(0.90<F 4<1.10)$ then output is C3 (Voltage Sag) \\
R4 & If $(F 1>0)$ or $(F 2>0),(F 3<0.1)$ and $(0.90<F 4<1.10)$ then output is C4 (Voltage Interruption) \\
\hline
\end{tabular}

From the Gabor Transform, the matrices for each case can be obtained from the time frequency representation. The values extracted are named as maximum values in GT matrix and used as features for this analysis. The maximum values in GT matrix for each event is plotted in and compare with RMS voltage graph as shown in Table 4. The results of classification showed that eighty numbers of voltage signals (pure sine wave, voltage swell, voltage sag and voltage interruption) were successfully detected and classified with classification accuracy of $100 \%$ respectively. The results of the classification are tabulated in Table 5.

Based on the results in Table 5, it was proven that the method of using maximum values in Gabor Transform matrix can detect and classify the voltage variation. The rule-based rules are implemented according to the IEEE Std with the features of maximum values in Gabor Transform matrix. The Gabor matrices of the voltage variation are plotted completely by their total number of nonzero elements which depends on the signal length as well as signal pattern where the matrices are associated with the matrix of

Voltage variations identification using gabor transform and rule-based classification method (Weihown Tee) 
window values along with the Gabor time slice. The output of Gabor Transform analysis is presented in complex form matrix where rows and columns present frequency and time data respectively. The information from the time-frequency contours will produce maimum Gabor Transform values. The oritentation of this is used to compare the graph plotting pattern with actual RMS graph of each case as shown in Table 4.

Table 4. Graph comparison between maximum values in GT matrix and RMS voltage of each case

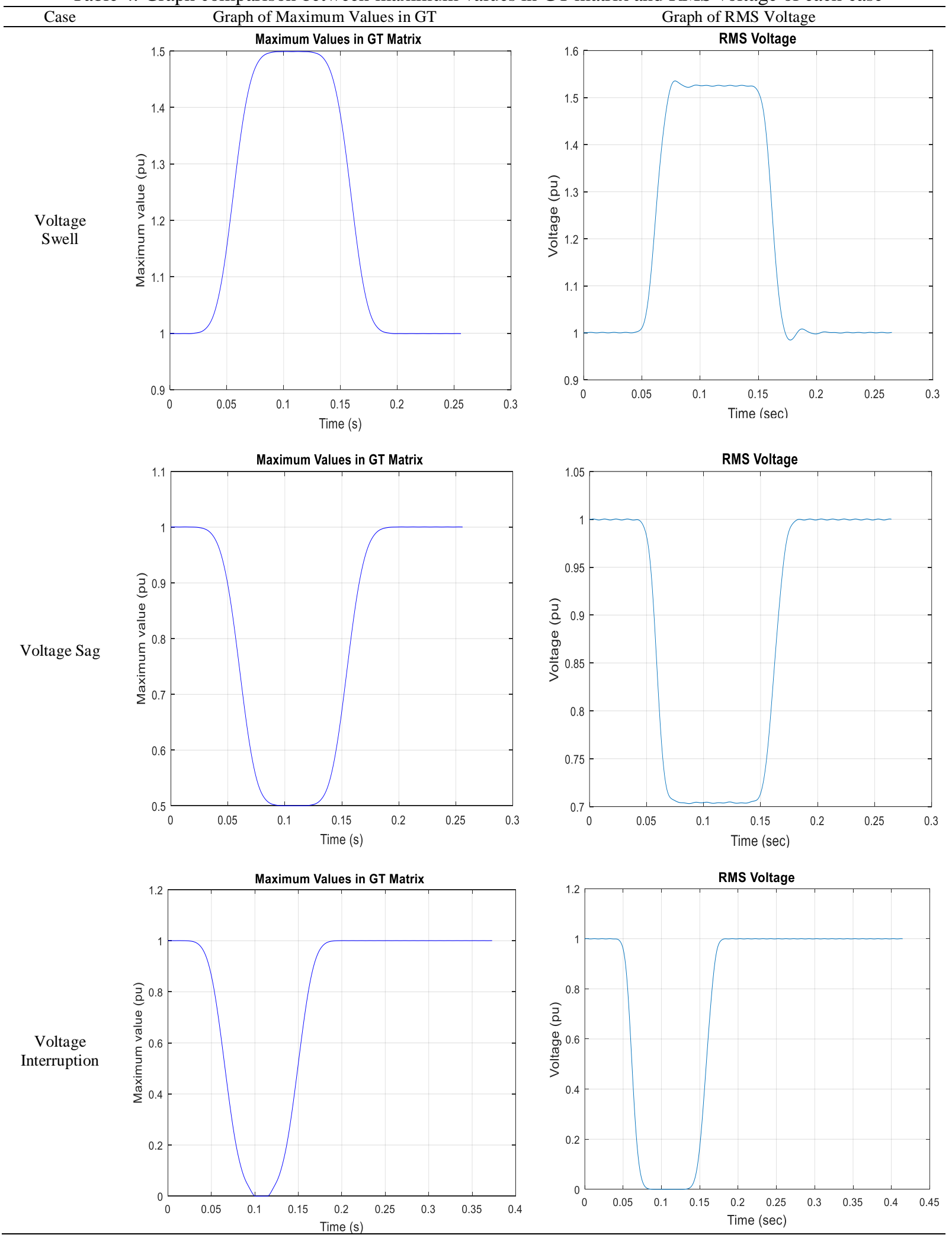


Table 5. Results on classification of voltage variation

\begin{tabular}{lllc}
\hline Class & Description & Number of signals & Classification accuracy (\%) \\
\hline C1 & Pure Sine Wave & 20 & 100 \\
C2 & Voltage Swell & 20 & 100 \\
C3 & Voltage Sag & 20 & 100 \\
C4 & Voltage Interruption & 20 & 100 \\
\hline
\end{tabular}

As can be seen in Table 4, the GT matrices of swell case show increase of values when time approaching $0.05 \mathrm{~s}$ and drop back to normal average value around $0.15 \mathrm{~s}$. The increment of values form pattern similar with RMS voltage graph for swell signal. For voltage sag case, the GT matrices show a decrement of values around period in between $0.05 \mathrm{~s}$ to $0.15 \mathrm{~s}$. As similar to the RMS voltage graph for voltage sag, the graph shows dropping in values in between period $0.05 \mathrm{~s}$ to $0.15 \mathrm{~s}$ and increases back to norminal value after that. In voltage interruption, the GT matrices values drop to zero within the $0.05 \mathrm{~s}$ to $0.15 \mathrm{~s}$ period. This pattern is understandable to be similar to RMS voltage pattern of voltage interruption where the values come to a halt during $0.05 \mathrm{~s}$ to $0.15 \mathrm{~s}$ period. From the results, the method of using maximum values of GT is applicated as the results pattern are similar to RMS voltage graphs calculated. This study has proven too that the voltage variation can be classified without using complicated classifier and method. Without using much features from the time frequency distribution, which may increase the computation time and memory of the system, the application of features of maximum values of GT matrices can contribute and provide appropriate information for the classification by using rule-based classifier.

\section{CONCLUSION}

In this paper, an easier method and technique to detect and classify voltage variation signals is introduced. The advantage of this technique is that it can be performed by other time-frequency analysis technique to acquire the features. Gabor Transform is used as it offers result of analysis in both time and frequency domains where features can be extracted from the matrixes. The features are then be used by rulebased classification method to detect and classify the disturbance waveforms respectively. The results obtained from the classification showed that the method and idea have good classification accuracy.

\section{ACKNOWLEDGEMENTS}

The author would like to thank Universiti Teknikal Malaysia Melaka (UTeM) for providing the research grant PJP/2017/FTK/HI14/S01546 for this research.

\section{REFERENCES}

[1] J. Huang and Z. Jiang, "Power Quality Assessment of Different Load Categories," in Energy Procedia, vol. 141, pp. 345-351, 2017.

[2] IEEE, "IEEE Recommended Practice and Requirements for Harmonic Control in Electric Power Systems," IEEE Std 519-2014 (Revision IEEE Std 519-1992), 2014.

[3] E. A. Nagata, D. D. Ferreira, C. A. Duque, and A. S. Cequeira, "Voltage sag and swell detection and segmentation based on Independent Component Analysis," Electr. Power Syst. Res., vol. 155, pp. 274-280, 2018.

[4] M. Bollen and I. Gu, "Signal processing of power quality disturbances, ” Wiley-IEEE Press, 2006.

[5] A. Rodríguez, J. A. Aguado, F. Martín, J. J. López, F. Muñoz, and J. E. Ruiz, "Rule-based classification of power quality disturbances using S-transform," Electr. Power Syst. Res., vol. 86, pp. 113-121, 2012.

[6] A. Abdullah and A. Sha'ameri, “ 2008 IEEE 2nd International Power and Energy Conference, no. PECon 08, pp. 313-317, 2008 .

[7] D. Ning, C. Wei, S. Juan, W. Jianwei, and X. Yonghai, "Voltage sag disturbance detection based on RMS voltage method," in Asia-Pacific Power and Energy Engineering Conference, APPEEC, 2009.

[8] S. Kamble and I. Dupare, "Detection of power quality disturbances using wavelet transform and artificial neural network," Emerg. Res. Areas Magn. Mach. Drives (AICERA/iCMMD), 2014 Annu. Int. Conf., pp. 1-5, 2014.

[9] M. B. I. Reaz, F. Choong, M. S. Sulaiman, F. Mohd-Yasin, and M. Kamada, "Expert system for power quality disturbance classifier," IEEE Trans. Power Deliv., vol. 22, no. 3, 2007.

[10] S. K. Meher and A. K. Pradhan, "Fuzzy classifiers for power quality events analysis," Electr. Power Syst. Res., vol. 80, no. 1, pp. 71-76, 2010.

[11] J. Han, W. Kim, J.-W. Lee, and C.-H. Kim, "Fault type classification in transmission line using STFT," 11th IET Int. Conf. Dev. Power Syst. Prot. (DPSP 2012), 2012.

[12] M. S. Manikandan, S. R. Samantaray, and I. Kamwa, "Detection and classification of power quality disturbances using sparse signal decomposition on hybrid dictionaries," IEEE Trans. Instrum. Meas., vol. 64, no. 1, pp. 27-38, 2015. 
[13] M. Jopri, A. Abdullah, T. Sutikno, and M. Manap, "A Utilisation of Improved Gabor Transform for Harmonic Signals Detection and Classification Analysis," International Journal of Electrical and Computer Engineering., vol. 7, no. 1, pp. 21-28, 2017.

[14] M. Szmajda, K. Górecki, and J. Mroczka, "Gabor transform, spwvd, gabor-wigner transform and wavelet transform - tools for power quality monitoring," Metrol. Meas. Syst., vol. 17, no. 3, 2010.

[15] D. A. Abraham, "Signal Processing," in Applied Underwater Acoustics: Leif Bjørnф, 2017.

[16] M. B. Latran and A. Teke, “A novel wavelet transform based voltage sag/swell detection algorithm,” Int. J. Electr. Power Energy Syst., vol. 71, pp. 131-139, 2015.

[17] Y. Gu and M. H. J. Bollen, "Time-frequency and time-scale domain analysis of voltage disturbances," IEEE Trans. Power Deliv., vol. 15, no. 4, 2000.

[18] M. Zhang, K. Li, and Y. Hu, “A real-time classification method of power quality disturbances," Electr. Power Syst. Res., vol. 81, no. 2, pp. 660-666, 2011.

[19] R. Naidoo and P. Pillay, "A new method of voltage sag and swell detection," IEEE Trans. Power Deliv., vol. 22, no. 2, pp. 1056-1063, 2007.

[20] N. Jrad, A. Kachenoura, I. Merlet, and F. Wendling, "Gabor transform for interictal high frequency oscillations classification," in 2015 International Conference on Advances in Biomedical Engineering, ICABME 2015, pp. $127-130,2015$.

[21] A. Subasi, "Classification of EMG signals using PSO optimized SVM for diagnosis of neuromuscular disorders," Comput. Biol. Med., vol. 43, no. 5, pp. 576-586, 2013.

[22] T. Jayasree, D. Devaraj, and R. Sukanesh, "Power quality disturbance classification using Hilbert transform and RBF networks," Neurocomputing, vol. 73, no. 7-9, pp. 1451-1456, 2010.

[23] M. Manjula, a. V. R. S. Sarma, and S. Mishra, "Detection and classification of voltage sag causes based on empirical mode decomposition," 2011 Annu. IEEE India Conf., 2011.

[24] S. Naderian and A. Salemnia, "Detection and classification of power-quality events using discrete Gabor transform and Support Vector Machine," in 6th Annual International Power Electronics, Drive Systems, and Technologies Conference, PEDSTC 2015, pp. 544-549, 2015.

[25] A. Banshwar and A. K. Chandel, "Identification of harmonic sources using fuzzy logic," $2010 \mathrm{Jt}$. Int. Conf. Power Electron. Drives Energy Syst. 2010 Power India, pp. 1-7, 2010.

[26] S. K. Meher and A. K. Pradhan, "Fuzzy classifiers for power quality events analysis," Electr. Power Syst. Res., vol. 80, no. 1, pp. 71-76, 2010.

[27] M. E. Salem, A. Mohamed, and S. A. Samad, "Rule based system for power quality disturbance classification incorporating S-transform features," Expert Syst. Appl., vol. 37, no. 4, pp. 3229-3235, 2010.

[28] D. Committee, I. Power, and E. Society, "IEEE Recommended Practice and Requirements for Harmonic Control in Electric Power Systems IEEE Power and Energy Society,” ANSI/IEEE Std. 519, 2014.

[29] W. Tee, M. R. Yusoff, A. R. Abdullah, M. H. Jopri, and N. S. N. Anwar, "Spectrogram Based Window Selection for the Detection of Voltage Variation," Int. J. of Integrated Engineering, vol. 11, no. 3, pp. 240-247, 2019.

[30] R. H. G. Tan and V. K. Ramachandaramurthy, "Numerical Model Framework of Power Quality Events," European Journal of Scientific Research, vol. 43, no. 1, pp. 30-47, 2010.

[31] M. Szmajda, K. Górecki, and J. Mroczka, "Gabor transform, Gabor-Wigner transform and SPWVD as a timefrequency analysis of power quality," in ICHQP 2010 - 14th International Conference on Harmonics and Quality of Power, 2010.

[32] S. Qian and D. Chen, "Discrete Gabor Transform," IEEE Trans. Signal Process., vol. 41, no. 7, pp. 2429-2438, 1993.

[33] M. H. Jopri, A. R. Abdullah, M. Manap, M. R. Yusoff, T. Sutikno, and M. F. Habban, "An improved detection and classification technique of harmonic signals in power distribution by utilizing spectrogram," International Journal of Electrical and Computer Engineering (IJECE), vol. 7, no. 1, pp. 12-20, 2017.

[34] N. Hamzah, A. Mohamed, and A. Hussain, "A new approach to locate the voltage sag source using real current component,” Electr. Power Syst. Res., vol. 72, no. 2, pp. 113-123, 2004.

[35] M. Zhang, K. Li, and Y. Hu, "A real-time classification method of power quality disturbances," Electric Power Systems Research, vol. 81, no. 2, pp. 660-666, 2011.

[36] M. H. W, Tee., Abdullah, A. R., Sutikno, T., Jopri, “A Comparative Modeling and Analysis of Voltage Variation by Using Spectrogram," TELKOMNIKA (Telecommunication, Computing, Electronics and Control), vol. 16, no. 5, pp. 2385-2394, 2018.

[37] R. Kumar, B. Singh, D. T. Shahani, A. Chandra, and K. Al-Haddad, "Recognition of Power-Quality Disturbances Using S-Transform-Based ANN Classifier and Rule-Based Decision Tree,” IEEE Trans. Ind. Appl., vol. 51, no. 2, pp. $1249-1258,2015$.

[38] W. Tee, M. R. Yusoff, A. R. Abdullah, and M. F. Yaakub, "Voltage variation signals source identification and diagnosis method," Int. J. Adv. Comput. Sci. Appl., vol. 10, no. 4, 2019. 


\section{BIOGRAPHIES OF AUTHORS}
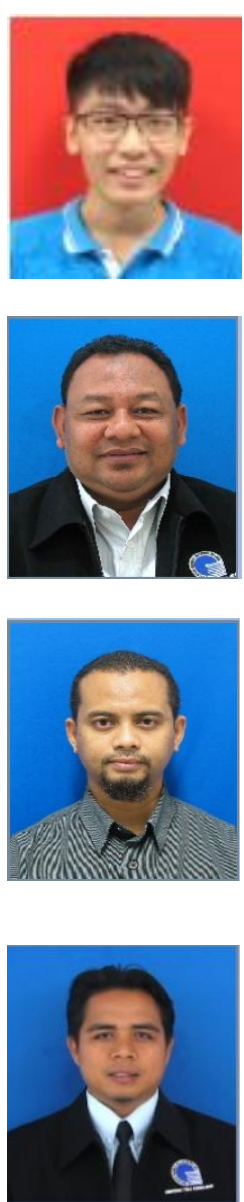

Tee Wei Hown was born in Selangor, Malaysia. He received his B.Eng in Engineering Technology from Universiti Teknikal Malaysia Melaka (UTeM) in 2017. Currently he is a postgraduate student researcher in power quality in electrical Engineering at Universiti Teknikal Malaysia Melaka (UTeM).

Assoc. Prof. Ts. Mohd Rahimi bin Yusoff was born in Kelantan, Malaysia. He received his B.Eng in Electrical \& Electronics from University of Wales, Swansea, UK in 1990, and M.Sc. in Electrical Engineering from University of Nottingham, England in 1992. Since 2010, he has been an academia staff in Universiti Teknikal Malaysia Melaka (UTeM) and currently holding the post as Dean of Faculty of Electrical and Electronic Engineering Technology. His research interests are power quality, signal processing and DSP application.

Muhamad Faizal bin Yaakub was born in Johor, Malaysia in 1981. In 2004 he received his B.Eng (Hons) degree in Electrical-Electronics Engineering from Universiti Teknologi Malaysia (UTM) and in 2013, he received his M.Eng in Electrical Engineering from Universiti Tun Hussein Onn Malaysia (UTHM). He has 5 years'experience in ASIC Test and Development in STMicroelectronics. He is currently a researcher and lecturer in Universiti Teknikal Malaysia Melaka (UTeM). He is registered as Chartered Engineer with UK Engineering Council and a member of Institute of Engineering and Technology. His research interest includes the field of multilevel inverter, sustainable energy technology and power quality engineering.

Assoc. Prof. Ir. Dr. Abdul Rahim bin Abdullah was born in Kedah, Malaysia. He received his B.Eng, Master Eng and PhD Degree from Universiti Teknologi Malaysia in 2001, 2004 and 2011 in electrical Engineering and digital signal Processing respectively. He is currently the Chief of Advanced Digital Signal Processing (ADSP) Lab in Universiti Teknikal Malaysia Melaka (UTeM). 